\title{
Modeling and Position-Sensorless Control of a Dual-Airgap Axial Flux Permanent Magnet Machine for Flywheel Energy Storage Systems
}

\author{
Trong Duy Nguyen ${ }^{\dagger}$, Gilbert Foo Hock Beng ${ }^{*}$, King-Jet Tseng ${ }^{*}$, \\ Don Mahinda Vilathgamuwa ${ }^{*}$, and Xinan Zhang ${ }^{*}$ \\ ${ }^{\dagger}$ School of Electrical and Electronic Eng., Nanyang Technological University, Singapore
}

\begin{abstract}
This paper presents the modeling and position-sensorless vector control of a dual-airgap axial flux permanent magnet (AFPM) machine optimized for use in flywheel energy storage system (FESS) applications. The proposed AFPM machine has two sets of three-phase stator windings but requires only a single power converter to control both the electromagnetic torque and the axial levitation force. The proper controllability of the latter is crucial as it can be utilized to minimize the vertical bearing stress to improve the efficiency of the FESS. The method for controlling both the speed and axial displacement of the machine is discussed. An inherent speed sensorless observer is also proposed for speed estimation. The proposed observer eliminates the rotary encoder, which in turn reduces the overall weight and cost of the system while improving its reliability. The effectiveness of the proposed control scheme has been verified by simulations and experiments on a prototype machine.
\end{abstract}

Keywords: Axial Levitation Force Control, Dual-Airgap Axial Flux Permanent Magnet Machines, Flywheel Energy Storage Systems, Sensorless vector control

\section{NOMENCLATURE}

$a$

$\delta$

$g_{1}, g_{2}$

$g_{10}, g_{20}$

G

$G_{f}$

$\wedge$

$i_{\alpha}, i_{\beta}$

$i_{d}, i_{q}$

$I_{\max }$

$J$

$K_{c}$

$K_{p}, K_{i}, K_{d}$

$K_{T}$

Manuscript received Aug. 19, 2011; revised Jul. 26, 2012

Recommended for publication by Associate Editor Jung-Ik Ha.

${ }^{\dagger}$ Corresponding Author: t.d.nguyen@pmail.ntu.edu.sg

Tel: +65-6790-6089, Fax: +65-6791-2687, Nanyang Tech. University

*School of Electrical\&Electronic Eng., Nanyang Technological University, Singapore

$\begin{array}{ll}L_{a s}, L_{b s}, L_{c s} & \text { stator self-inductance } \\ L_{f f} & \text { rotor self-inductance } \\ L_{s} & \text { stator inductance } \\ l_{m 1}, l_{m 2} & \text { upper and lower permanent magnet thickness } \\ \lambda_{\alpha}, \lambda_{\beta} & \alpha \beta \text {-axes stator flux linkages } \\ \lambda_{\alpha}^{r}, \lambda_{\beta}^{r} & \alpha \beta \text {-axes rotor fluxes } \\ \lambda_{d}, \lambda_{q} & \text { dq-axes stator flux linkages } \\ \lambda_{f} & \text { rotor flux linkages } \\ \left|\lambda_{s}\right| & \text { stator flux linkage magnitude } \\ M_{a f}, M_{b f}, M_{c f} & \text { mutual inductances } \\ \mu_{0}, \mu_{r} & \text { permeability in vacuum, relative permeability } \\ N_{f} i_{f} & \text { fictious magnetomotive force of the rotor's field } \\ N_{s} & \text { number of stator windings } \\ \omega_{n} & \text { undamped natural frequency of the system } \\ \omega_{s} & \text { stator flux vector speed } \\ \omega_{r e} & \text { rotor electrical speed } \\ p & \text { number of pole pairs } \\ \xi & \text { damping ratio of the system } \\ R & \text { stator resistance } \\ R_{i}, R_{o} & \text { inner and outer radius of the permanent magnets } \\ T_{1}, T_{2}, T & \text { upper, lower and total motor's rotating torque }\end{array}$




$\begin{array}{ll}T_{d} & \text { differential time constant of a PID controller } \\ \theta & \text { rotor electrical angular position } \\ \theta_{r e} & \text { rotor electrical position } \\ v_{\alpha}, v_{\beta} & \alpha \beta \text {-axes stator voltages } \\ V_{d c} & \text { dc-link voltage } \\ Z & \text { axial displacement of the flywheel }\end{array}$

\section{INTRODUCTION}

Due to recent advances in power electronics and major improvements in materials and bearing technology, the FESS has become a promising alternative to conventional chemical battery energy storage systems [1]-[3]. The FESS has attributes that make it attractive for use in both terrestrial and space applications. In terrestrial application it can be used in hybrid and electric vehicles, electric rails, and shipyard crane applications, renewable energy applications, distributed generation for power smoothing, power leveling and voltage restoring [3]-[8], and in space applications it can be used for energy storage and attitude control functions [9]-[11]. The motor/generator is the key component responsible for the three fundamental modes of the FESS: charge, standby and discharge. Therefore, the modeling and control of the motor/generator for the FESS is amongst the key tasks for optimizing its performance.

Axial-flux PM machines are gaining increasing attention in applications which require geometric constraints and the use of traditional PM machines are not appropriate [12]-[15]. Due to advances in machine design, AFPM machines can have a number of distinct advantages over conventional radial-flux PM machines, such as: a higher torque, better power density and lower noise during operation [16]-[19]. It has also been shown that single air-gap axial flux machines [20]-[23] can generate substantial axial forces which have to be counteracted by shaft bearings. In the machine proposed for electric vehicles in [20], field control is used to produce a compensating axial force to balance the axial force between the rotor and the stator. However, this method requires complicated control schemes and efforts in axial force compensation, which may limit the range of the electromagnetic torque. Dual air-gap axial flux machines are used in [19], [24]-[26] where the total axial force is equal to the difference between the two attractive forces of the two air-gaps, and a wider range of field control capability can be achieved. However, these systems have other complications such as the requirement of two power electronic converters to drive the three-phase AC currents [25], [26] or two different converters for the AC currents and for the DC field current drive [19]. In addition, they were not specially designed for FESS applications.

Field-oriented control has been utilized to control the motor/generator in a FESS [10], [27]. In these schemes, continuous rotor-position information is required. Encoders

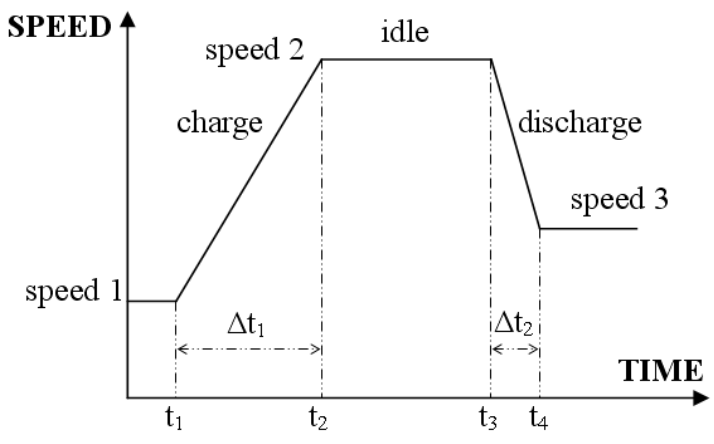

Fig. 1. A typical speed profile of the FESS.

can be used to detect position signals. However, rotary encoders hardly satisfy the wide speed range operation, especially in a FESS. This is due to limitation in terms of the mechanism and manufacturing for such rotary encoders. In addition, the presence of an encoder presents several drawbacks, such as increased cost and reduced system reliability. Hence it is desirable to eliminate this sensor.

In this paper, a modeling and position-sensorless control scheme for the dual-airgap AFPM machines [15] used in FESS applications is proposed. This AFPM machine has two sets of three-phase stator windings but requires only a single power converter to supply power to control both the axial force and the electromagnetic torque. Its application in a FESS is realized by orientating its axial direction vertically and having its double-sided rotor be the core of the flywheel. Unlike the scheme introduced in [28], the sensorless operation in this paper is achieved by adopting a novel inherent speed sensorless stator flux observer. The proposed observer is immune to speed estimation errors, stator resistance variations and dc-offset effects. This allows it to deliver accurate flux and speed estimation over a wide speed range. The global asymptotic stability of botfliluthe observer and stator resistance estimator are guaranteed by the Lyapunov stability analysis. The proposed position-sensorless control scheme is in conjunction with the key requirements for the optimized performance of the FESS; i.e, fast acceleration/deceleration of the motor/generator for the fast charging/discharging energy of the FESS at a reduced cost and weight. Simulations together with experimental results on a machine prototype are presented to confirm the effectiveness of the control scheme.

\section{THE DUAL-AIRGAP AFPM MACHINE}

A FESS is often designed to work as a fast-response energy storage device. A typical speed profile of a FESS is shown in Fig. 1, and it can change with the load demand. Acceleration and deceleration of the motor/generator in short periods of time is essential in a FESS. Therefore, high 


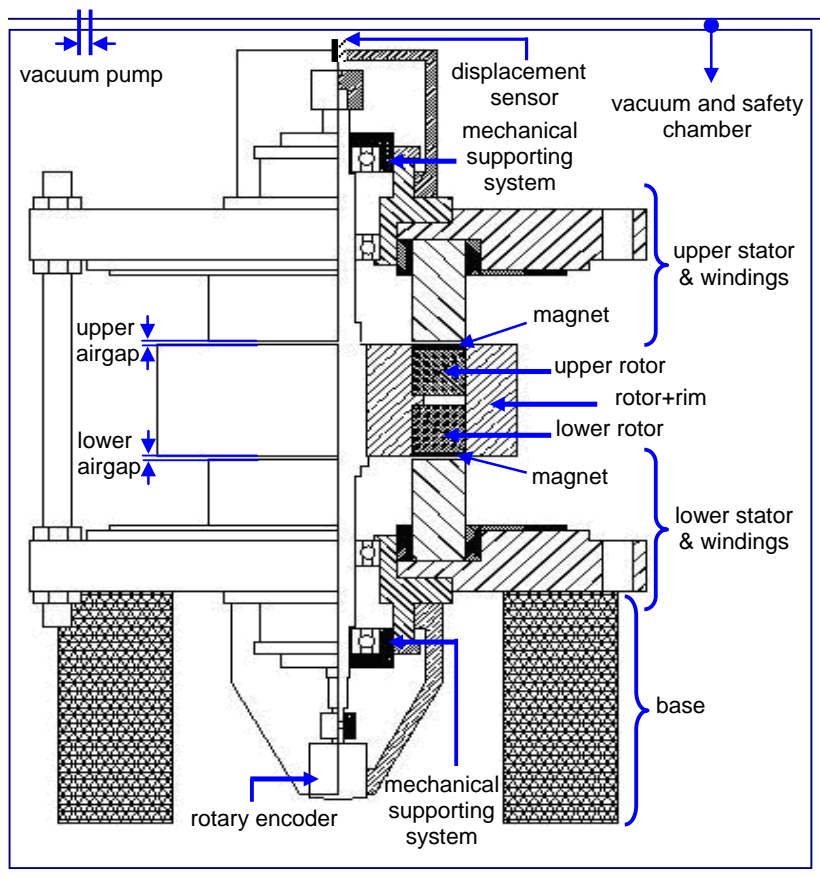

Fig. 2. Main components of the dual-airgap AFPM machine in a simplified FESS.

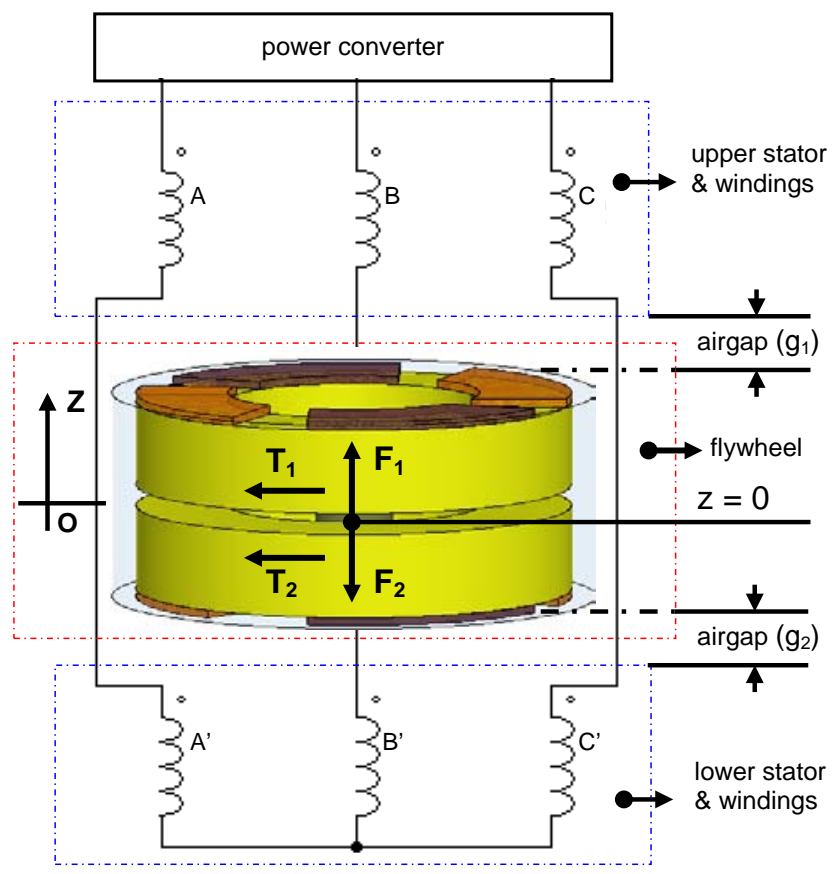

Fig. 3. Illustration of the dual-airgap AFPM machine principle.

performance control combining the minimization of the axial-force stress and the frictional losses on the bearings is amongst the main concerns of this study.

The main components of the dual-airgap AFPM machine in a simplified FESS are illustrated in Fig. 2. They are composed of the stators, windings, rotors, rim, permanent magnets, shafts, bearings and mechanical supporting system. The
TABLE I

PROTOTYPE DimENSIONS AND PARAMETERS

\begin{tabular}{lc}
\hline \hline Rated power & $1 \mathrm{kVA}$ \\
Rated current, rms & $1.66 \mathrm{~A}$ \\
Rated voltage, rms & $350 \mathrm{~V}$ \\
Phase resistance & $4.67 \Omega$ \\
dq-axes inductances & $26.8 \mathrm{mH}$ \\
Rated frequency & $200 \mathrm{~Hz}$ \\
Moment of inertia & $0.49 \mathrm{~kg} . \mathrm{cm}^{2}$ \\
Number of pole pairs & 2 \\
Magnet type & $\mathrm{NdFeB}$ \\
Remanent flux density & $1.23 \mathrm{~T}$ \\
Upper stator winding turns & 210 \\
Lower stator winding turns & 210 \\
Stator outer diameter & $90 \mathrm{~mm}$ \\
Stator inner diameter & $52 \mathrm{~mm}$ \\
Airgap length & $0.5 \mathrm{~mm}$ \\
Number of slots & 24 \\
Teeth width & $12.40 \mathrm{~mm}$ \\
Slot depth & $18 \mathrm{~mm}$ \\
Permanent magnet length of upper & $2.0 \mathrm{~mm}$ \\
rotor & \\
Permanent magnet length of lower & $1.87 \mathrm{~mm}$ \\
rotor & \\
\hline \hline
\end{tabular}

machine is comprised of two halves namely the upper half and the lower half, respectively. Each upper or lower half has its own stator, rotor, magnets and windings but their rotors are integrated together by the shaft. The compact flywheel is formed by the two rotors which are encircled by a carbon-fiber composite rim. The flywheel is sandwiched in between two disk-type 24-slot stators. Each of the upper and lower stators carries a set of three-phase copper windings which are the double-layer type with 2 slots per pole per phase [29]. Rotation of the flywheel is supported radially by the two main bearings which can be either based on conventional steel or on advanced ceramic materials [30], [31]. Another set of auxiliary bearings, named the mechanical supporting system, provides axial support. In operation, the flywheel is physically constrained by this supporting system.

The winding connection diagram and the principle of the proposed machine are illustrated in Fig. 3. The upper and lower three-phase stator windings are connected in series. Hence only one power electronic converter is necessary to operate the machine. In general, the power converter works under the pulse width modulation (PWM) condition to energize the three-phase windings. In operation, for example, in the upper airgap, the rotor flux travels axially from the upper rotor pole to the upper stator and then back to the rotor. The rotating flux generated by the currents in the upper stator windings interacts with the rotor flux and then 


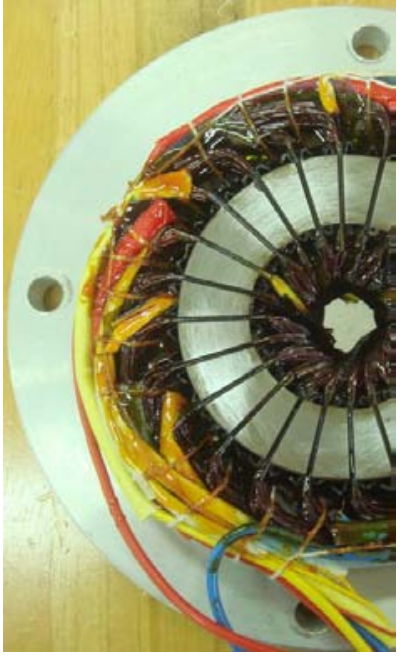

(a)

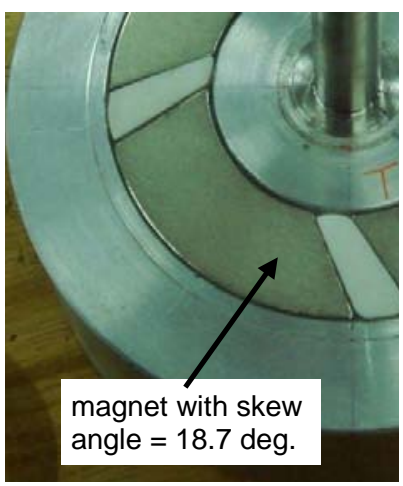

(b)
Fig. 4. Machine prototype: (a) 24-slot stator with its three-phase windings. (b) Rotor with surface-mounted permanent magnets.

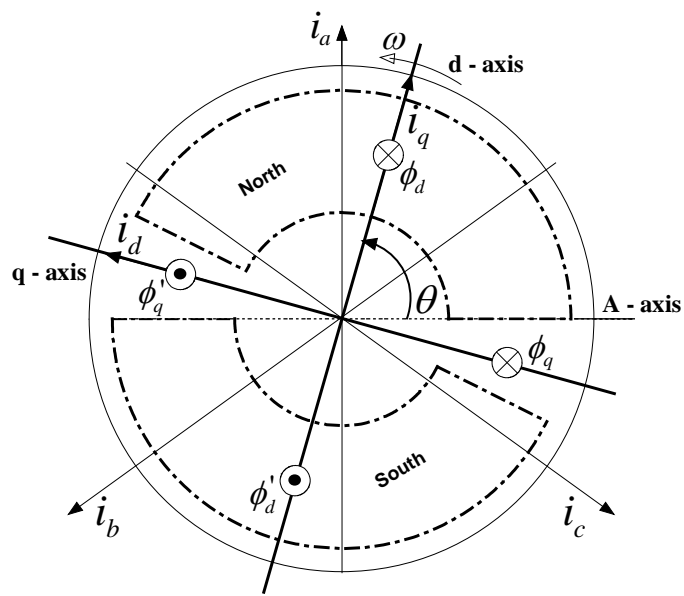

Fig. 5. Three phase $(a, b, c)$ and rotating $(d, q)$ windings of a 2-pole AFPM machine.

generates electromagnetic torque and axial force, namely $T_{1}$, $F_{1}$, as illustrated in Fig. 4. The torque and axial force of the lower machine half, $T_{2}$ and $F_{2}$, are derived similarly. The net force along the axial axis $(O Z)$ is obtained as:

$$
F=F_{1}-F_{2}
$$

The total electromagnetic torque is written as:

$$
T=T_{1}+T_{2}
$$

In this AFPM machine, the total electromagnetic torque is used to control the rotation of the flywheel, while the net axial force is used to regulate the axial stress on the bearing support. The parameters and dimensions of the dual-airgap AFPM machine studied in this paper are shown in Table I.

\section{Modeling AND CONTROL OF THE DUAL-AIRGAP AFPM MACHINE}

\section{A. Mathematical Model}

The separate stator and rotor of the dual-airgap AFPM machine are shown in Fig. 4. The permanent magnets are mounted on the surface of a disk-type rotor, as shown in Fig. 4(b). Thus this machine can be analytically analyzed as a non-salient PM machine. The analytical approach used for a traditional radial flux machine is employed here to derive the mathematical model for this dual-airgap AFPM machine.

With the help of the supporting system, the upper and lower airgaps of this machine are adjusted to be equal to each other, $g_{1}=g_{2}$. The model of the dual-airgap AFPM machine is firstly obtained on the basis of the coordinate axes of a 2-pole AFPM machine. The analysis is valid for a general case, and it is then extended for a $2 p$-pole machine. The three-phase windings and the $d q$-winding layout of the 2-pole AFPM machine are shown in Fig. 5. The rotating $d$ and $q$-axis windings are in quadrature of each other and their magnetic axes are aligned with the $d$ - and $q$-axis of the rotor. The $d$-axis of the rotor is chosen to be aligned with the center lines of the magnets and the $q$-axis lies between the magnets.

The phase voltage equation of a typical 3-phase AC machine can be expressed as:

$$
v_{A B C}=R i_{A B C}+\frac{d \lambda_{A B C}}{d t}
$$

By using Park's transformation, the 3-phase variables of an AC machine can be written in the rotor reference frame (dq0) as:

$$
\left[X_{d q 0}\right]=\left[K_{P}\right]\left[X_{A B C}\right]
$$

As presented in the above section, the machine is composed of two halves. Therefore the model of one machine half can be obtained first and the other half can then be derived in a similar manner.

For either of the two halves of this machine, assuming that the permanent magnets on the rotor are represented by the magnetomotive force of $N_{\mathrm{f}} i_{\mathrm{f}}$, and ignoring the leakage inductances, the flux matrix of the machine half can be expressed as:

$$
\lambda=\left(\begin{array}{llll}
\lambda_{f} & \lambda_{a} & \lambda_{b} & \lambda_{c}
\end{array}\right)^{T}=\left(\begin{array}{llll}
L_{f f} & M_{a f} & M_{b f} & M_{c f} \\
M_{a f} & L_{a s} & M_{a b} & M_{a c} \\
M_{b f} & M_{b a} & L_{b s} & M_{a c} \\
M_{c f} & M_{c a} & M_{c b} & L_{c s}
\end{array}\right)\left(\begin{array}{l}
i_{f} \\
i_{a} \\
i_{b} \\
i_{c}
\end{array}\right)
$$

where: 


$$
\begin{gathered}
L_{a s}=L_{b s}=L_{c s}=L_{s}=\frac{\mu_{0} \pi\left(R_{o}^{2}-R_{i}^{2}\right) N_{s}{ }^{2}}{8 P^{2} g} \\
L_{f f}=L_{f}=\frac{\mu_{0} \pi\left(R_{o}^{2}-R_{i}^{2}\right) N_{f}{ }^{2}}{8 P^{2} g} \\
M_{a f}=\frac{\mu_{0} \pi\left(R_{o}^{2}-R_{i}^{2}\right) N_{s} N_{f}}{8 P^{2} g} \cos \theta=L_{m} \cos \theta \\
M_{b f}=\frac{\mu_{0} \pi\left(R_{o}^{2}-R_{i}^{2}\right) N_{s} N_{f}}{8 P^{2} g} \cos (\theta-2 / 3 \pi)=L_{m} \cos (\theta-2 / 3 \pi) \\
M_{c f}=\frac{\mu_{0} \pi\left(R_{o}^{2}-R_{i}^{2}\right) N_{s} N_{f}}{8 P^{2} g} \cos (\theta+2 / 3 \pi)=L_{m} \cos (\theta+2 / 3 \pi)
\end{gathered}
$$

In the rotor-reference frame, the linkage flux matrix in (5) is transformed into:

$$
\left[\begin{array}{l}
\lambda_{f} \\
\lambda_{d} \\
\lambda_{q}
\end{array}\right]=\left(\begin{array}{ccc}
L_{f} & \frac{3}{2} L_{m} & 0 \\
L_{m} & \frac{3}{2} L_{s} & 0 \\
0 & 0 & \frac{3}{2} L_{s}
\end{array}\right)\left[\begin{array}{l}
i_{f} \\
i_{d} \\
i_{q}
\end{array}\right]
$$

The axial force and electromagnetic torque can be expressed as:

$$
\begin{aligned}
& F_{S}=-\frac{\partial W_{c o}}{\partial g}=-\frac{\partial\left[\frac{1}{2}\left(\begin{array}{lll}
i_{f} & i_{d} & i_{q}
\end{array}\right)\left(\begin{array}{lll}
\lambda_{f} & \lambda_{d} & \lambda_{q}
\end{array}\right)^{T}\right]}{\partial g} \\
& =\frac{\mu_{0} \pi\left(R_{o}^{2}-R_{i}^{2}\right)}{16 P^{2} g^{2}}\left[N_{f}^{2} i_{f}^{2}+\frac{5}{2} N_{s} N_{f} i_{d} i_{f}+\frac{3}{2} N_{s}^{2}\left(i_{d}^{2}+i_{q}^{2}\right)\right] \\
& T_{s}=\frac{3}{2} \times P\left(\lambda_{d} i_{q}-\lambda_{q} i_{d}\right)=\frac{3 \mu_{0} \pi\left(R_{o}^{2}-R_{i}^{2}\right) N_{s} N_{f}}{16 P g} i_{f} i_{q}
\end{aligned}
$$

The effective air-gaps between the stator and the rotor at the equilibrium point are obtained as:

$$
\begin{aligned}
& g_{10}=K_{c}\left(g_{1}+l_{m 1} / \mu_{r}\right) ; \\
& g_{20}=K_{c}\left(g_{2}+l_{m 2} / \mu_{r}\right)
\end{aligned}
$$

The force $F_{1}$ and the torque $T_{1}$ which are generated by the upper machine half can be calculated by substituting $g=g_{10}-z$, $i_{d}=i_{d 1}, i_{q}=i_{q 1}$ and $N_{f} i_{f}=N_{f 1} i_{f 1}$ into the equations, whereas the force $F_{2}$ and the torque $T_{2}$ which are generated by the lower machine half can be calculated by substituting $g=g_{20}-z, i_{d}=$ $i_{d 2}, i_{q}=i_{q 2}$ and $N_{f} i_{f}=N_{f 2} i_{f 2}$ into the equations. The total axial force and the rotating torque can be expressed as:

$$
F=F_{1}-F_{2}=\frac{\mu_{0} \pi\left(R_{o}^{2}-R_{i}^{2}\right)}{16 P^{2}}\left\{\begin{array}{l}
\frac{N_{f 1}^{2} i_{f 1}^{2}+\frac{5}{2} N_{s} N_{f 1} i_{d 1} i_{f 1}+\frac{3}{2} N_{s}^{2}\left(i_{d 1}^{2}+i_{q 1}^{2}\right)}{\left(g_{10}-z\right)^{2}} \\
-\frac{N_{f 2}^{2} i_{f 2}^{2}+\frac{5}{2} N_{s} N_{f 2} i_{d 2} i_{f 2}+\frac{3}{2} N_{s}^{2}\left(i_{d 2}^{2}+i_{q 2}^{2}\right)}{\left(g_{20}+z\right)^{2}}
\end{array}\right\}
$$

$$
T=T_{1}+T_{2}=\frac{3 \mu_{0} \pi\left(R_{o}^{2}-R_{i}^{2}\right) N_{s}}{16 P}\left[\frac{N_{f 1} i_{f 1} i_{q 1}}{g_{10}-Z}+\frac{N_{f 2} i_{f 2} i_{q 2}}{g_{20}+Z}\right]
$$

\section{B. Speed Control}

Since the upper and lower windings are connected in series, (14) can be transformed into:

$$
T=\frac{3 \mu_{0} \pi\left(R_{o}^{2}-R_{i}^{2}\right) N_{s}}{16 P}\left[\frac{N_{f 1} i_{f 1}}{g_{10}-z}+\frac{N_{f 2} i_{f 2}}{g_{20}+z}\right] \times i_{q}
$$

Since $z$ is much smaller than $g_{10}$ and $g_{20},(15)$ is simplified into:

$T=\frac{3 \mu_{0} \pi\left(R_{o}^{2}-R_{i}^{2}\right) N_{s}}{16 P} \times\left(\frac{N_{f 1} i_{f 1}}{g_{10}}+\frac{N_{f 2} i_{f 2}}{g_{20}}\right) \times i_{q}=K_{T} i_{q}$

The dynamic rotating equation can be written as follows:

$$
\frac{d \omega}{d t}=\frac{1}{J} T_{e}=\frac{K_{T}}{J} i_{q}
$$

which can be transformed into:

$$
\begin{aligned}
& \theta(s)=\frac{1}{s} \varpi(s) \\
& \varpi(s)=\frac{K_{T}}{J s} I_{q}(s)
\end{aligned}
$$

A proportional integral (PI) controller is used to control the machine speed.

\section{Axial Displacement Control}

To simplify the model, it is assumed that the radial motion of the rotor is stabilized by radial bearings. Therefore, the axial displacement of the rotor is independent of the radial motion. (13) then can be re-written as:

$$
F=\frac{\mu_{0} \pi\left(R_{o}^{2}-R_{i}^{2}\right)}{16 P^{2}}\left\{\begin{array}{l}
\frac{\left(N_{f 1}^{2} i_{f 1}^{2}+\frac{5}{2} N_{s} N_{f 1} i_{f 1} i_{d}+\frac{3}{2} N_{s}^{2}\left(i_{d}^{2}+i_{q}^{2}\right)\right)}{\left(g_{10}-z\right)^{2}} \\
-\frac{\left(N_{f 2}^{2} i_{f 2}^{2}+\frac{5}{2} N_{s} N_{f 2} i_{f 2} i_{d}+\frac{3}{2} N_{s}^{2}\left(i_{d}^{2}+i_{q}^{2}\right)\right)}{\left(g_{20}+z\right)^{2}}
\end{array}\right\}
$$

Defining the following relationship of $i_{d}$ and $i_{c d}$ :

$$
i_{d}=I_{d 0}+i_{c d}
$$

Then by linearizing (18) about $z=0$ and $i_{d}=I_{d 0}$, and expanding it into the Taylor series to the first order term, the axial force equation is transformed into: 


$$
\begin{aligned}
& F\left(z, i_{d}\right) \approx F_{\left(z_{0}, I_{d 0}\right)}+\frac{\partial F_{\left(z_{0}, I_{d 0}\right)}}{\partial z} \cdot\left(z-z_{0}\right)+\frac{\partial F_{\left(z_{0}, I_{d 0}\right)}}{\partial i_{d}} \cdot\left(i_{d}-I_{d 0}\right) \\
& \Leftrightarrow F \approx K_{1}+K_{2} z+K_{3} i_{c d}
\end{aligned}
$$

where:

$$
\begin{aligned}
& \left.K_{1}=F_{\left(z_{0}, I_{d 0}\right)}=K \times\left\{\begin{array}{l}
\frac{1}{g_{10}^{2}}\left(N_{f 1}^{2} i_{f 1}^{2}+\frac{5}{2} N_{s} N_{f 1} i_{f 1} I_{d 0}+\frac{3}{2} N_{s}^{2}\left(I_{d 0}^{2}+i_{q}^{2}\right)\right) \\
-\frac{1}{g_{20}^{2}}\left(N_{f 2}^{2} i_{f 2}^{2}+\frac{5}{2} N_{s} N_{f 2} i_{f 2} I_{d 0}+\frac{3}{2} N_{s}^{2}\left(I_{d 0}^{2}+i_{q}^{2}\right)\right)
\end{array}\right\}\right\} \\
& K_{2}=\frac{\partial F_{\left(z_{0}, I_{d 0}\right)}}{\partial z}=-K \times\left\{\begin{array}{l}
\frac{1}{g_{10}^{3}}\left(N_{f 1}^{2} i_{f 1}^{2}+\frac{5}{2} N_{s} N_{f 1} i_{f 1} I_{d 0}+\frac{3}{2} N_{s}^{2}\left(I_{d 0}^{2}+i_{q}^{2}\right)\right) \\
+\frac{1}{g_{20}^{3}}\left(N_{f 2}^{2} i_{f 2}^{2}+\frac{5}{2} N_{s} N_{f 2} i_{f 2} I_{d 0}+\frac{3}{2} N_{s}^{2}\left(I_{d 0}^{2}+i_{q}^{2}\right)\right)
\end{array}\right\} \\
& K_{3}=\frac{\partial F_{\left(z_{0}, I_{d 0}\right)}}{\partial i_{d}}=K \times\left\{\begin{array}{l}
\frac{1}{g_{10}^{2}}\left(\frac{5}{2} N_{s} N_{f 1} i_{f 1}+3 N_{s}^{2} I_{d 0}\right) \\
-\frac{1}{g_{20}^{2}}\left(\frac{5}{2} N_{s} N_{f 2} i_{f 2}+3 N_{s}^{2} I_{d 0}\right)
\end{array}\right\}
\end{aligned}
$$

and $K=\frac{\mu_{0} \pi\left(R_{o}^{2}-R_{i}^{2}\right)}{16 P^{2}}$

In (22), the gravitational force acting on the rotor is designed to be similar to the value of $K_{1}$ using a repetitive procedure. The axial displacement $z$ is maintained at the equilibrium point $z=0$, which makes the term $K_{2} z$ negligible. The term $K_{3} i_{c d}$ is a dynamic value which is used to control the levitation force.

The dynamic equation in the axial motion is then expressed as:

$$
m \frac{d^{2} z}{d^{2} t}=K_{1}+K_{2} z+K_{3} i_{c d}-G_{f}
$$

Using the Laplace transformation, (23) becomes:

$$
\begin{aligned}
& m s^{2} z(s)=K_{2} z(s)+K_{3} i_{c d}(s)+\frac{K_{1}-G_{f}}{s} \\
& z(s)=\frac{K_{3}}{m s^{2}-K_{2}} i_{c d}(s)+\frac{K_{1}-G_{f}}{m s^{3}-K_{2} s}
\end{aligned}
$$

A proportional integral derivative (PID) controller is used to regulate the axial variation, and the transfer function of the PID controller can be written as:

$$
G_{c}(s)=K_{p}+\frac{K_{i}}{s}+K_{d} s
$$

The control structure is drawn as illustrated in Fig. 6. The characteristic polynomial of the system is obtained as:

$$
\begin{aligned}
& m s^{3}+K_{3} K_{d} s^{2}+\left(K_{3} K_{p}-K_{2}\right) s+K_{3} K_{i}=0 \\
& \Leftrightarrow s^{3}+\frac{K_{3} K_{d}}{m} s^{2}+\frac{\left(K_{3} K_{p}-K_{2}\right)}{m} s+\frac{K_{3} K_{i}}{m}=0
\end{aligned}
$$

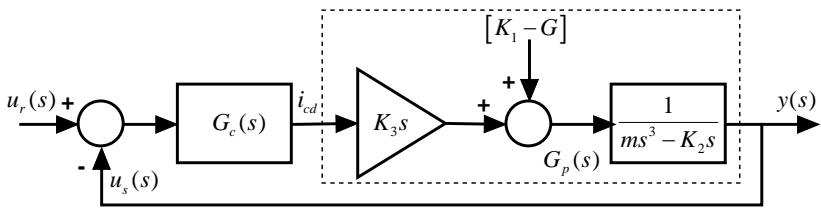

Fig. 6. Diagram of axial displacement control using PID controller.

A suitable closed-loop characteristic equation for a third-order system is:

$$
(s+a)\left(s^{2}+2 \xi \omega_{n} s+\omega_{n}^{2}\right)=0
$$

By identifying the characteristic polynomial with (27), $K_{p}, K_{i}$ and $K_{d}$ are obtained.

\section{POSITION-SENSORLESS CONTROL}

The key factor that affects the performance of a sensorless drive is the accuracy of the stator flux observer. Due to their robustness to parameter variations and disturbance rejection capabilities, speed adaptive observers are commonly used. In a digital realization, speed adaptation is usually performed as the last step in the estimation process. Hence the speed estimate is affected by cumulative errors, noise and delays. When an inaccurate speed value is fed back to the observer, the flux and speed estimation gradually worsen. Since speed adaptive observers result in a coupling between the flux and speed estimators, non-speed adaptive observers are desirable.

In the stationary $(\alpha-\beta)$ reference frame, the rotor flux is defined as:

$$
\begin{aligned}
& \lambda_{\alpha}^{r}=\lambda_{f} \cos \theta_{r e}=\lambda_{\alpha}-L_{s} i_{\alpha} \\
& \lambda_{\beta}^{r}=\lambda_{f} \sin \theta_{r e}=\lambda_{\beta}-L_{s} i_{\beta}
\end{aligned}
$$

The stator flux linkage is governed by:

$$
\begin{aligned}
& \lambda_{\alpha}=\int\left(v_{\alpha}-R_{s} i_{\alpha}\right) d t \\
& \lambda_{\beta}=\int\left(v_{\beta}-R_{s} i_{\beta}\right) d t
\end{aligned}
$$

Neglecting the linearization errors, differentiating (28) and rearranging the terms result in a modified current model for the AFPM machine.

$$
\frac{d}{d t}\left(\begin{array}{l}
i_{\alpha} \\
i_{\beta}
\end{array}\right)=\left(\begin{array}{cc}
-\frac{R_{s}}{L_{s}} & 0 \\
0 & -\frac{R_{s}}{L_{s}}
\end{array}\right)\left(\begin{array}{l}
i_{\alpha} \\
i_{\beta}
\end{array}\right)+\frac{1}{L_{s}}\left(\begin{array}{cc}
0 & \omega_{r e} \\
-\omega_{r e} & 0
\end{array}\right)\left(\begin{array}{l}
\lambda_{\alpha}^{r} \\
\lambda_{\beta}^{r}
\end{array}\right)+\frac{1}{L_{s}}\left(\begin{array}{l}
v_{\alpha} \\
v_{\beta}
\end{array}\right)
$$




$$
\frac{d}{d t}\left(\begin{array}{l}
\lambda_{\alpha}^{r} \\
\lambda_{\beta}^{r}
\end{array}\right)=-\left(\begin{array}{cc}
0 & \omega_{r e} \\
-\omega_{r e} & 0
\end{array}\right)\left(\begin{array}{c}
\lambda_{\alpha}^{r} \\
\lambda_{\beta}^{r}
\end{array}\right)
$$

\section{A. Observer Synthesis}

Define the matrix $\Phi$ as:

$$
\Phi=-\left(\begin{array}{cc}
0 & \omega_{r e} \\
-\omega_{r e} & 0
\end{array}\right)\left(\begin{array}{c}
\lambda_{\alpha}^{r} \\
\lambda_{\beta}^{r}
\end{array}\right)
$$

It can be observed that the matrix $\Phi$ appears as a common term in both (30) and (31). Therefore, the matrix $\Phi$ can be replaced by a sliding mode function that provides its estimate upon convergence.

$$
\left(\begin{array}{c}
S_{\alpha} \\
S_{\beta}
\end{array}\right)=\hat{\Phi}=\left(\begin{array}{cc}
0 & \hat{\omega}_{r e} \\
-\hat{\omega}_{r e} & 0
\end{array}\right)\left(\begin{array}{c}
\hat{\lambda}_{\alpha}^{r} \\
\hat{\lambda}_{\beta}^{r}
\end{array}\right)
$$

where $\left(\begin{array}{l}S_{\alpha} \\ S_{\beta}\end{array}\right)=G_{o} \operatorname{sign}\left(\begin{array}{l}\tilde{i}_{\alpha} \\ \tilde{i}_{\beta}\end{array}\right) ; \quad \tilde{i}_{\alpha}=i_{\alpha}-\hat{i}_{\alpha}$ and $\tilde{i}_{\beta}=i_{\beta}-\hat{i}_{\beta}$ are the current estimation errors. Furthermore, a sliding mode current observer without speed adaptation can be designed as follows.

$$
\frac{d}{d t}\left(\begin{array}{c}
\hat{i}_{\alpha} \\
\hat{i}_{\beta}
\end{array}\right)=\left(\begin{array}{cc}
-\frac{R_{s}}{L_{s}} & 0 \\
0 & -\frac{R_{s}}{L_{s}}
\end{array}\right)\left(\begin{array}{l}
i_{\alpha} \\
i_{\beta}
\end{array}\right)+\frac{1}{L_{s}}\left(\begin{array}{c}
v_{\alpha} \\
v_{\beta}
\end{array}\right)+\frac{G_{o}}{L_{s}} \operatorname{sign}\left(\begin{array}{c}
\tilde{i}_{\alpha} \\
\tilde{i}_{\beta}
\end{array}\right)
$$

\section{B. Lyapunov Stability Analysis}

By subtracting (34) from (30), the current estimation error dynamics are given by:

$$
\frac{d}{d t}\left(\begin{array}{c}
\tilde{i}_{\alpha} \\
\tilde{i}_{\beta}
\end{array}\right)=-\left(\begin{array}{cc}
0 & \omega_{r e} \\
-\omega_{r e} & 0
\end{array}\right)\left(\begin{array}{c}
\lambda_{\alpha}^{r} \\
\lambda_{\beta}^{r}
\end{array}\right)-\frac{G_{o}}{L_{s}} \operatorname{sign}\left(\begin{array}{c}
\tilde{i}_{\alpha} \\
\tilde{i}_{\beta}
\end{array}\right)
$$

Define a Lyapunov candidate function as:

$$
V=\frac{1}{2}\left(\tilde{i}_{\alpha}^{2}+\tilde{i}_{\beta}^{2}\right)>0
$$

Differentiating (36) both sides yields:

$$
\begin{aligned}
& \dot{V}=\dot{\tilde{i}}_{\alpha} \tilde{i}_{\alpha}+\dot{\tilde{i}}_{\beta} \tilde{i}_{\beta}=\omega_{r e}\left[\tilde{i}_{\alpha} \lambda_{\alpha}^{r}-\tilde{i}_{\beta} \lambda_{\beta}^{r}\right]-\frac{G_{o}}{L_{s}}\left[\left|\tilde{i}_{\alpha}\right|+\left|\tilde{i}_{\beta}\right|\right] \\
& \text { For stability, } \dot{V}<0 \text { or } G_{o}>\frac{\omega_{r e} L_{s}\left[\tilde{i}_{\alpha} \lambda_{\alpha}^{r}-\tilde{i}_{\beta} \lambda_{\beta}^{r}\right]}{\left[\left|\tilde{i}_{\alpha}\right|+\left|\tilde{i}_{\beta}\right|\right]} \text {. By }
\end{aligned}
$$

selecting a large enough gain $G_{o}$, the convergence of the current observer can be guaranteed. In fact, there is no upper bound on the gain $G_{o}$, making it very easy to tune for satisfactory performance.

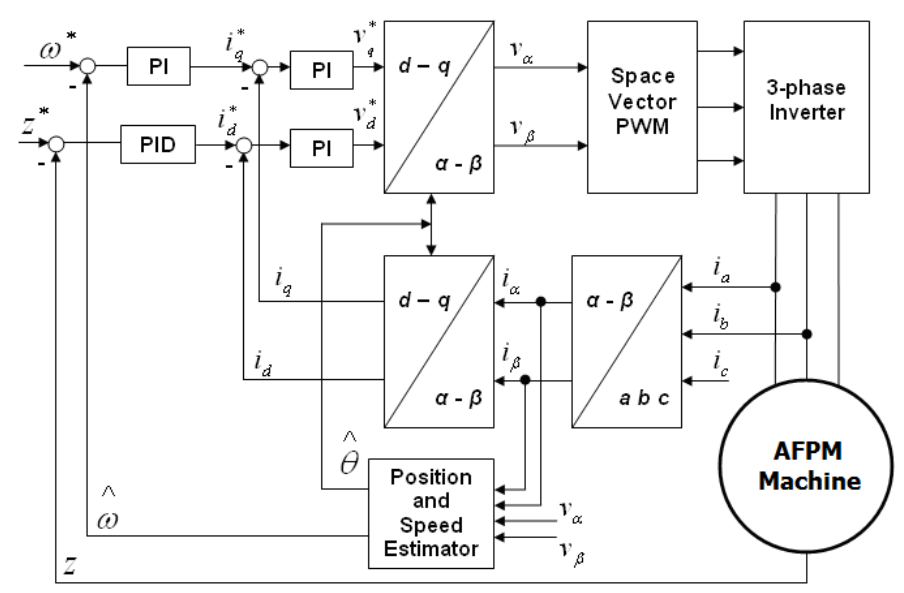

Fig. 7. Control system diagram.

\section{Rotor Speed and Position Estimation}

After the sliding mode action occurs, the rotor flux is a mere integration of the sliding mode functions without requiring any information on the rotor speed as dictated by:

$$
\frac{d}{d t}\left(\begin{array}{c}
\hat{\lambda}_{\alpha}^{r} \\
\hat{\lambda}_{\beta}^{r}
\end{array}\right)=-\left(\begin{array}{c}
S_{\alpha} \\
S_{\beta}
\end{array}\right)
$$

The rotor position can then be retrieved from:

$$
\hat{\theta}_{r e}=\tan ^{-1}\left(\frac{\hat{\lambda}_{\beta}^{r}}{\hat{\lambda}_{\alpha}^{r}}\right)
$$

Multiplying the first and second rows of (33) by $\hat{\lambda}_{\beta}^{r}$ and $\hat{\lambda}_{\alpha}^{r}$, respectively, and rearranging the terms gives the rotor speed estimate:

$$
\hat{\omega}_{r e}=\frac{\hat{\lambda}_{\beta}^{r} S_{\alpha}-\hat{\lambda}_{\alpha}^{r} S_{\beta}}{\hat{\lambda}_{\alpha}^{r 2}+\hat{\lambda}_{\beta}^{r 2}}
$$

The speed signal is low-pass filtered to remove noise. This is a compact yet effective speed estimation scheme. It can be seen that the estimation scheme is dependent on the voltage information, and that its performance can be degraded in low speed or zero speed operation. However, it is well suited for this AFPM machine designed for FESS applications.

\section{CONTROL System}

Based on the rotor-flux oriented vector control, the d- and q-axis currents of the flywheel can be decoupled and controlled separately. From the torque and axial force equations (16) and (22) it can be seen that torque and the force can be controlled independently of rotor's rotation and axial levitation. 


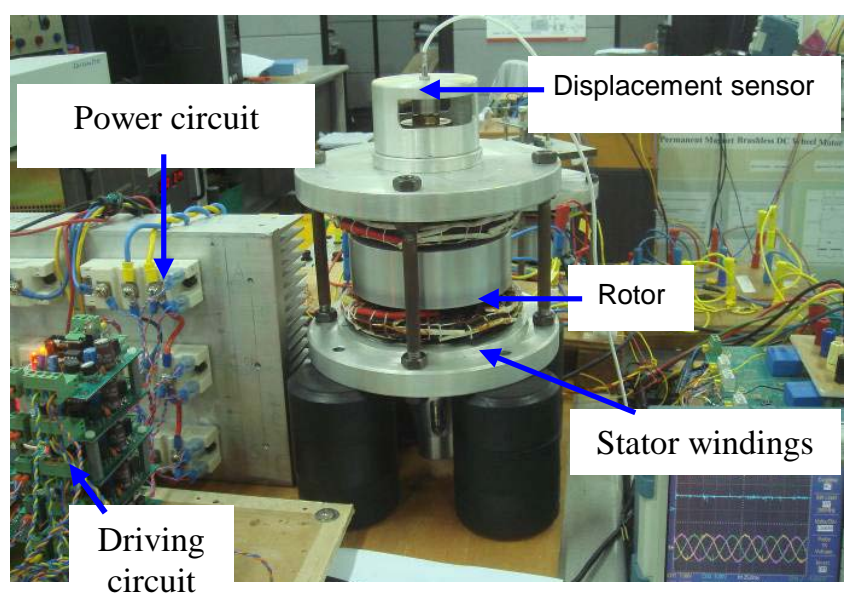

Fig. 8. Experimental setup.

The overall flywheel system block diagram is shown in Fig. 7. Information on the rotor angle is estimated from the stator current and the voltage reference. PID controllers are used to control the speed, axial displacement and to regulate the dand q-axis currents. The rotational angular speed $\omega$ is estimated and then compared with the speed command $\omega^{*}$, the speed error signal $\omega^{*}-\omega$ is amplified in the PI controller as the torque component current command $i_{q}^{*}$ in the rotational coordinate. Similarly, the error between $z$ and $z$ * are amplified by the PID controllers to generate the current command $i_{d}{ }^{*}$. The space vector modulation technique is applied to control a voltage source inverter to supply the three-phase pulse width modulation voltage as calculated by the controllers to feed the flywheel.

\section{EXPERIMENTAL RESULTS}

\section{A. Experimental Setup}

A machine prototype is developed and tested. The stator yoke is constructed from laminated iron which is enrolled and compacted as a spiral. In that way, the radial flux is minimized and mainly the axial paths are used to conduct the magnetic flux. The permanent magnets are made of neodymium-iron-boron (NdFeB35) with a Ni-Cu-Ni coating. The experimental setup is shown in Fig. 8. The axial displacement is measured by an eddy-current type displacement sensor and a rotary encoder is installed to measure the real rotor angle for verification.

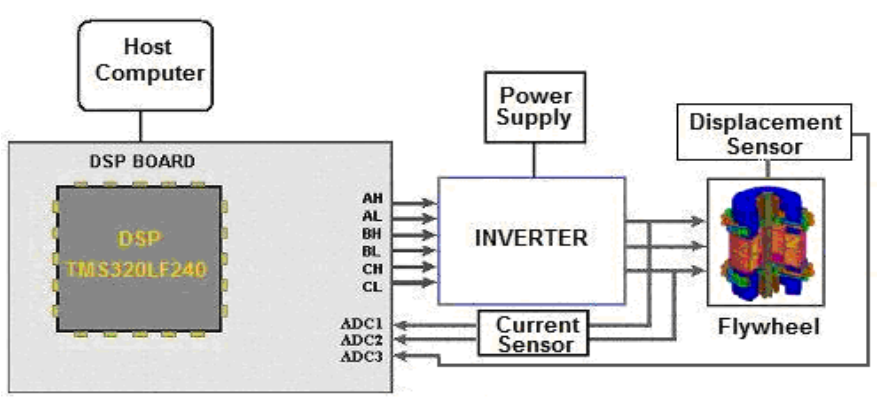

Fig. 9. Control system diagram of the flywheel device.

The experimental control setup is shown in Fig. 9. The speed and axial displacement are supervised and controlled by a digital signal processor TMS320LF240 embedded in a dSPACE 1103 card together with a personal computer.

\section{B. Experimental Results}

Experiments are performed with a pulse width modulation frequency of $10 \mathrm{kHz}$ and a sampling time of $100 \mu \mathrm{s}$. All the data were captured and displayed in dSPACE ControlDesk by the personal computer. The AFPM machine was repeatedly accelerated and decelerated from $500 \mathrm{rpm}$ to $1,000 \mathrm{rpm}$ to simulate the charging and discharging operation of the FESS. The axial displacement reference is set at zero throughout. Both the speed and axial displacement responses are well controlled. They are depicted in Fig. 10. There are some small variations in the displacement during the acceleration and deceleration of the machine. This is due to the interaction between $i_{d}$ and $i_{q}$ in the force equation as derived in (20). The corresponding $d q$-axes currents are shown in Fig. 11. The speed estimation error in Fig. 12 infers that the speed estimation process of the observer is effective since the estimation error is very small with an average value of zero. The speed error, as seen in Fig. 12, is due to the low resolution of the installed rotary encoder at 1,024 pulses / revolution. The speed profile during the startup of this AFPM machine is also obtained and shown in Fig. 13. The reference, measured and estimated values are shown. It can be seen that the estimate follows the reference very well. This confirms the effectiveness of the sensorless control scheme applied to this AFPM machine. The minimum speed of 100rpm is obtained and shown in the first subplot of Fig. 14. The speed error is shown in the second subplot. It can be seen that drive system also works well at this minimum speed and that the speed performance deteriorates in the low speed region. However, operation at such a low speed is unrealistic for a typical FESS. The minimum operating speed for appreciable energy storage in a FESS should be approximately 300rpm. 

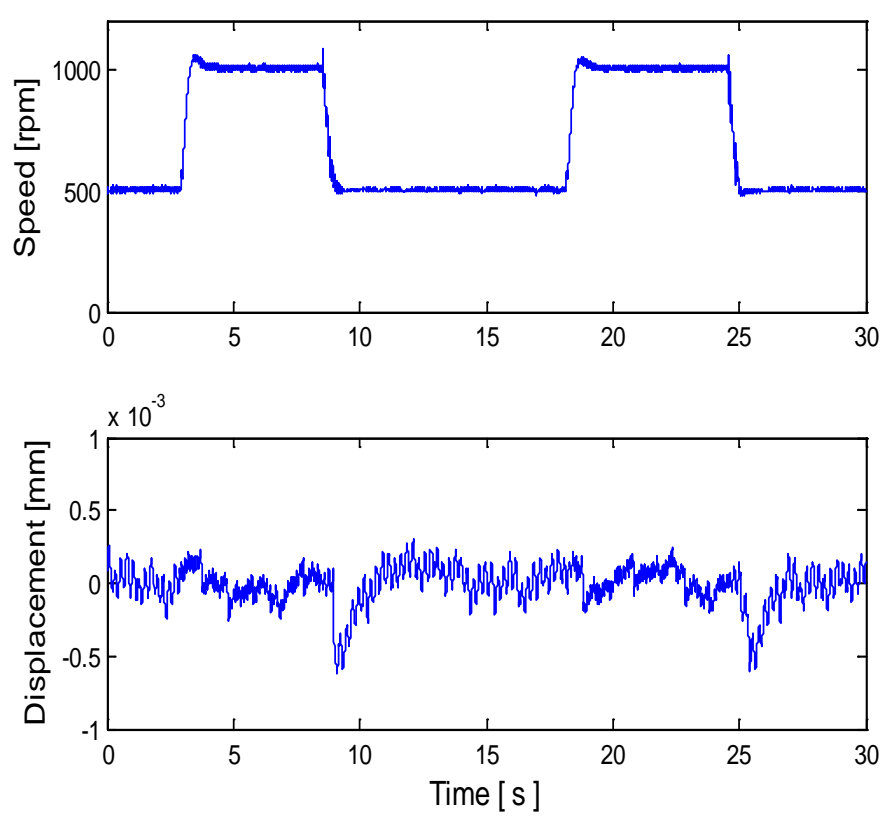

Fig. 10. Experimental results of the proposed position sensorless AFPM drive: speed profile, and axial displacement respectively.
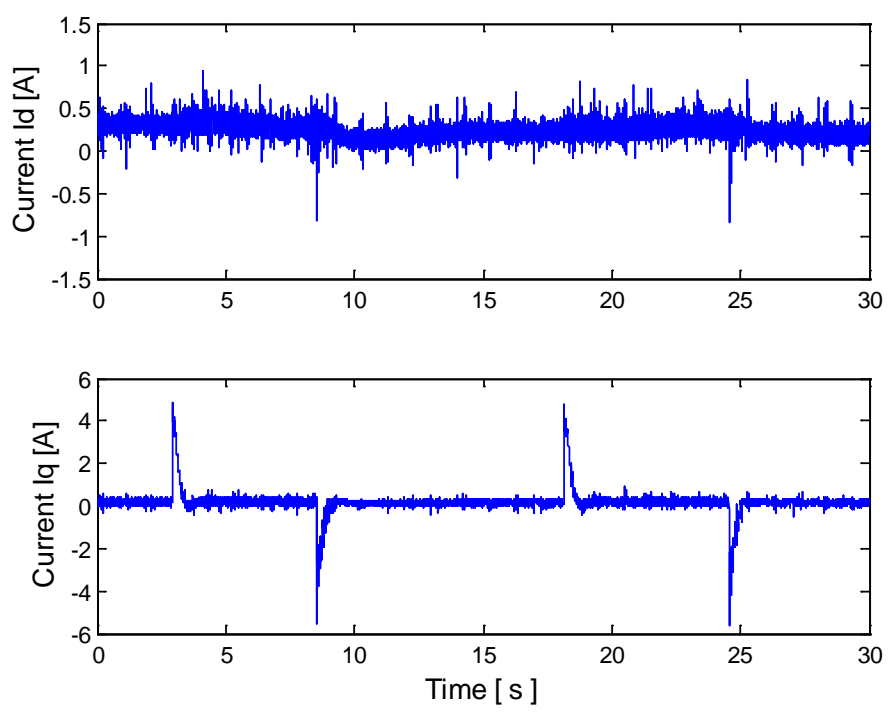

Fig. 11. Current responses of the proposed position sensorless AFPM drive with speed profile in Fig. 10. First and second subplots show the $d$-and q- axis currents respectively.

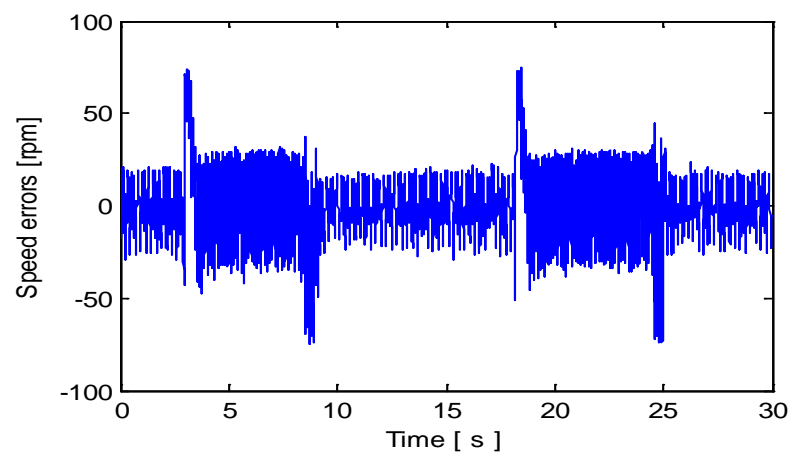

Fig. 12. Speed estimation error for speed profile in Fig. 10.

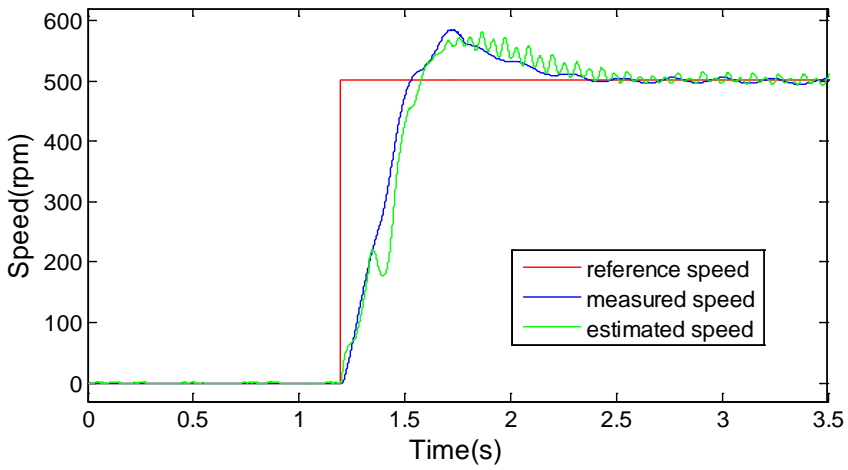

Fig. 13. Speed profile during startup.
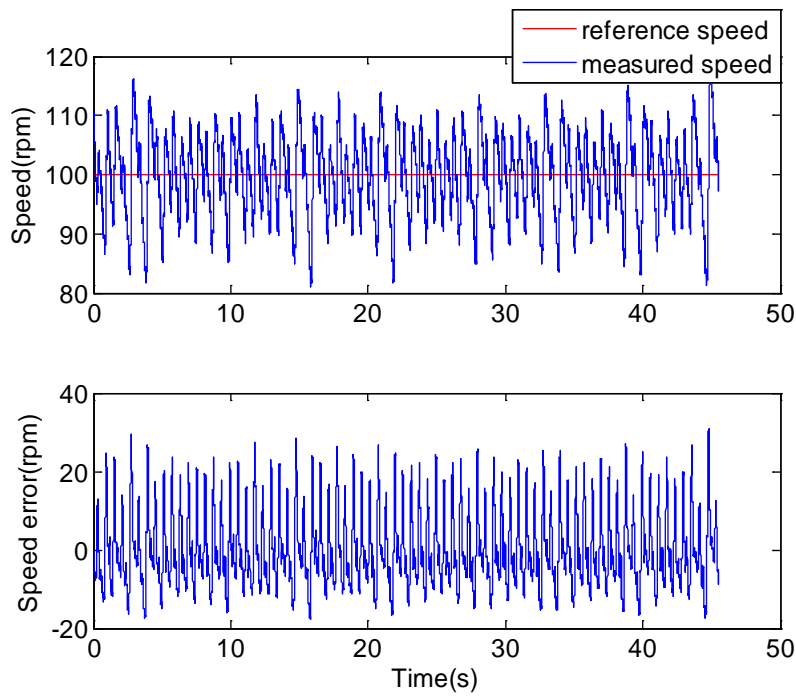

Fig. 14. Minimum operating speed and speed error.

\section{CONCLUSION}

The modeling and position-sensorless vector control of a dual-airgap axial flux permanent magnet machine optimized for use in flywheel energy storage system applications is presented in this paper. The machine has two sets of three-phase stator windings but it only requires a single power converter to simultaneously control both the electromagnetic torque and the axial levitation force. The method for controlling the speed and axial displacement of the machine is discussed. An inherent speed sensorless observer is also proposed for speed estimation. The proposed observer eliminates the rotary encoder, which in turn reduces the overall weight and cost of the system while improving its reliability. The effectiveness of the proposed control scheme has been verified by simulations and experiments on a prototype machine. 


\section{REFERENCES}

[1] J. G. Bitterly, "Flywheel technology: past, present, and 21st century projections,” IEEE Aerosp. Electron. Syst. Mag., Vol. 13, No. 8, pp. 13-16, Aug. 1998.

[2] R. Hebner, J. Beno, A. Walls, and M. J. Riezenman, "Flywheel batteries come around again,” IEEE Spectr., Vol. 39, No. 4, pp. 46-51, Apr. 2002.

[3] P. Fairley, "Flywheels keep the grid in tune," IEEE Spectr., Vol. 48, No. 7, pp. 16-18, Jul. 2011.

[4] G. Cimuca, S. Breban, M. M. Radulescu, C. Saudemont, and B. Robyns, "Design and control strategies of an induction-machine-based flywheel energy storage system associated to a variable-speed wind generator," IEEE Trans. Energy Convers., Vol. 25, No. 2, pp. 526-534, Jun. 2010.

[5] W. Lei, E. G. Collins, and L. Hui, "Optimal design and real-time control for energy management in electric vehicles," IEEE Trans.Veh. Technol., Vol. 60, No. 4, pp. 1419-1429, May 2011.

[6] R. Cardenas, et al., "Power smoothing using a flywheel driven by a switched reluctance machine,” IEEE Trans. Ind. Electron., Vol. 53, No. 4, pp. 1086-1093, Jun. 2006.

[7] X.-D. Sun, K.-H. Koh, B.-G. Yu, and M. Matsui, "Fuzzy-logic-based v/f control of an induction motor for a dc grid power-leveling system using flywheel energy storage equipment," IEEE Trans. Ind. Electron., Vol. 56, No. 8, pp. 3161-3168, Aug. 2009.

[8] B. Wang and G. Venkataramanan, "Dynamic voltage restorer utilizing a matrix converter and flywheel energy storage," IEEE Trans. Ind. Appl., Vol. 45, No. 1, pp. 222-231, Jan./Feb. 2009.

[9] L. Eunjeong, "Microsatellite combined attitude/energy systems," IEEE Aerosp. Electron. Syst. Mag., Vol. 19, No. 4, pp. 27-32, Apr. 2004.

[10]B. H. Kenny, R. Jansen, P. Kascak, T. Dever, and W. Santiago, "Integrated power and attitude control with two flywheels," IEEE Aerosp. Electron. Syst. Mag., Vol. 41, No. 4, pp. 1431-1449, Oct. 2005.

[11]B. H. Kenny, P. E. Kascak, R. Jansen, T. Dever, and W. Santiago, "Control of a high-speed flywheel system for energy storage in space applications,” IEEE Trans.Ind. Appl., Vol. 41, No. 4, pp. 1029-1038, Jul./Aug. 2005.

[12]F. Caricchi, F. Maradei, G. D. Donato, and F. G. Capponi, "Axial-flux permanent-magnet generator for induction heating gensets,” IEEE Trans. Ind. Electron., Vol. 57, No. 1, pp. 128 - 137, Jan. 2010.

[13]A. Mebarki, K. Wejrzanowski, M. Shanel, and N. L. Brown, “A high-power, totally enclosed, permanent magnet, axial flux machine for engine integration," in Power Electronics, Machines and Drives (PEMD 2010), 5th IET International Conference on, pp. 1-6, 2010.

[14]P. Zheng, J. Zhao, R. Liu, C. Tong, and Q. Wu, "Magnetic characteristics investigation of an axial-axial flux compound-structure pmsm used for hevs,” IEEE Trans. Magn., Vol. 46, No. 6, pp. 2191 - 2194, Jun. 2010.

[15]T. D. Nguyen, K.-J. Tseng, S. Zhang, and H. T. Nguyen, "A novel axial flux permanent magnet machine for flywheel energy storage system: design and analysis,” IEEE Trans. Ind. Electron., No. 99, 2010.

[16]K. Sitapati and R. Krishnan, "Performance comparisons of radial and axial field, permanent-magnet, brushless machines," IEEE Trans. Ind. Appl., Vol. 37, No. 5, pp. 1219-1226, Sep./Oct. 2001.

[17]A. Cavagnino, M. Lazzari, F. Profumo, and A. Tenconi, “A comparison between the axial flux and the radial flux structures for PM synchronous motors,” IEEE Trans. Ind. Appl., Vol. 38, No. 6, pp. 1517-1524, Nov./Dec. 2002.

[18]M. Aydin, S. Huang, and T. A. Lipo, "Torque quality and comparison of internal and external rotor axial flux surface-magnet disc machines,” IEEE Trans. Ind. Electron., Vol. 53, No. 3, pp. 822-830, Jun. 2006.

[19]M. Aydin, S. Huang, and T. A. Lipo, "Design, Analysis and Control of a Hybrid Field Controlled Axial Flux Permanent
Magnet Motor,” IEEE Trans. Ind. Electron., Vol. 57, No. 1, pp. 78-87, Jan. 2010.

[20]C.-T. Liu, T.-S. Chiang, J. F. D. Zamora, and S.-C. Lin, "Field-oriented control evaluations of a single-sided permanent magnet axial-flux motor for an electric vehicle," IEEE Trans. Magn., Vol. 39, No. 5, pp. 3280 - 3282, Sep. 2003.

[21]F. Marignetti, V. D. Colli, and Y. Coia, "Design of axial flux pm synchronous machines through 3-d coupled electromagnetic thermal and fluid-dynamical finite-element analysis," IEEE Trans. Ind. Electron., Vol. 55, No. 10, pp. 3591-3601, Oct. 2008.

[22]T.-S. Kwon, S.-K. Sul, L. Alberti, and N. Bianchi, "Design and control of an axial-flux machine for a wide flux-weakening operation region,” IEEE Trans. Ind. Appl., Vol. 45, No. 4, pp. 1258-1266, Jul./Aug. 2009.

[23]J. H. Choi, J. H. Kim, D. H. Kim, and Y. S. Baek, "Design and Parametric Analysis of Axial Flux PM Motors With Minimized Cogging Torque,” IEEE Trans. Magn., Vol. 45, No. 6, Jun. 2009.

[24]D. A. Gonzalez-Lopez, J. A. Tapia, R. Wallace, and A. Valenzuela, "Design and test of an axial flux permanent-magnet machine with field control capability,” IEEE Trans. Magn., Vol. 44, No. 9, pp. 2168 - 2173, Sep. 2008.

[25]Q. D. Nguyen and S. Ueno, "Analysis and Control of Nonsalient Permanent Magnet Axial Gap Self-Bearing Motor,” IEEE Trans. Ind. Electron., Vol. 58, No. 7, pp. 2644-2652, Jul. 2011.

[26]N. Quang Dich and S. Ueno, "Modeling and control of salient-pole permanent magnet axial-gap self-bearing motor," IEEE/ASME Trans. Mechatronics, Vol. 16, No. 3, pp. 518-526, Jun. 2011.

[27]R. Cardenas, R. Pena, G. Asher, and J. Clare, "Power smoothing in wind generation systems using a sensorless vector controlled induction Machine driving a flywheel," IEEE Trans. Energy Convers., Vol. 19, No. 1, pp. 206-216, Mar. 2004.

[28] N. Trong Duy, T. King Jet, Z. Chi, Z. Shao, and N. Hoan Thong, "Position sensorless control of a novel flywheel energy storage system,” in IPEC, 2010 Conference Proceedings, pp. 1192-1198, 2010.

[29]A. K. Sawhney, A Course in Electrical Machine Design, Dhanpat Rai \& Sons, 1987.

[30]M. Nosaka, S. Takada, M. Yoshida, M Kikuchi, T. Sudo, and S. Nakamura, "Improvement of durability of hybrid ceramic ball bearings in liquid hydrogen at 3 million dn (120,000 rpm)," Tribology Online, Vol. 5, No. 1, pp. 60-70, Feb. 2010.

[31]Q. He, H. Liu, Y. Zhang, J. Ye, and Q. Niu, "The characteristics of hybrid ceramic ball bearing for high-speed spindle " International Conference on Mechatronics and Automation, (ICMA 2009), pp. 2489-2494, 2009.

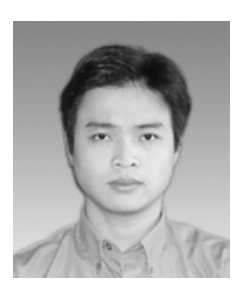

Trong Duy Nguyen was born in Binh Dinh, Vietnam. He received his B.Eng. and M.Eng. from the Hochiminh-City University of Technology, Vietnam, and his Ph.D from the Nanyang Technological University, Singapore. He is currently with Nanyang Technological University, Singapore, as a Postdoctoral Research Fellow. His current research interests include electrical machine design and drives, electromagnetics, and electrical energy conversion systems. 


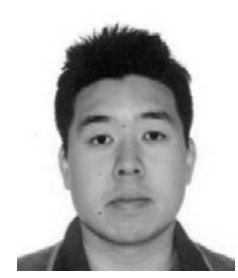

Gilbert Foo Hock Beng received his Diploma in Electrical and Electronics Engineering (with distinction) from INTI College, Subang Jaya, Malaysia, in 2004. He received his B.S. in Electrical Engineering (with first-class honors) and his Ph.D. from the University of New South Wales, Sydney, Australia, in 2007 and 2010, respectively. He is currently a Research Fellow at Nanyang Technological University, Singapore. His current research interests include electrical machines and drives. Dr. Foo is a member of the IEEE Industrial Electronics Society, the IEEE Power Electronics Society, and the IEEE Industry Applications Society. His research interests are in electrical machines and drives. Dr. Foo is a member of the IEEE Industrial Electronics Society, the IEEE Power Electronics Society, and the IEEE Industry Applications Society.

King-Jet Tseng was born in Singapore. He received his B.Eng. (First Class) and M.Eng. from the National University of Singapore, Singapore, and his Ph.D. from Cambridge University, Cambridge, U.K. He is currently the Head of Power Engineering and the Director of the Centre for Smart Energy Systems at Nanyang Technological University, Singapore. He has actively conducted courses and provided technical consultation for industries and institutions in Singapore and other countries. He has held key advisory appointments in various governmental organizations of the Singapore government. He has published over a hundred technical papers, and actively reviews and edits papers for major journals and conferences. Dr. Tseng is a Fellow of the Cambridge Commonwealth Society and the Cambridge Philosophical Society. He is a Senior Member of the Institute of Engineers, Singapore, a Corporate Member of the Institution of Engineering and Technology (UK), and a Senior Member of the Institute of Electrical and Electronic Engineers (USA). In 1996, he was awarded the Swan Premium by the Institution of Electrical Engineers (UK), for his work on gate turn-off thyristors for use in traction drives. He has held a number of major appointments in professional societies including the Chair of IEEE Singapore Section in 2005. He is a Chartered Engineer registered in UK. He was awarded the IEEE Third Millennium Medal and the IEEE Region Ten Outstanding Volunteer Award.

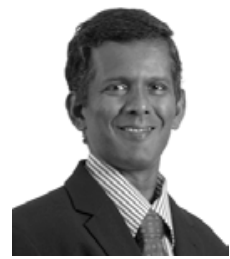

Don Mahinda Vilathgamuwa received his B.S. in Electrical Engineering from the University of Moratuwa, Sri Lanka, and his Ph.D. in Electrical Engineering from Cambridge University, UK, in 1985 and 1993, respectively. In 1993 Dr Vilathgamuwa joined the School of Electrical and Electronic Engineering, Nanyang Technological University, Singapore, as a Lecturer, and he is now an Associate Professor. His current research interests include micro-grids, design of grid interfaces for renewable energy systems and power converters.

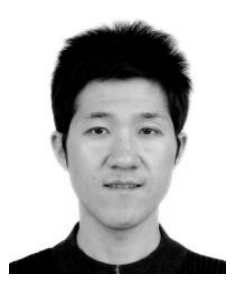

and motor drives.
Xinan Zhang received his B.Eng. from Fudan University, Shanghai, China (PRC), in 2008. He was with the Chinese Academy of Sciences as a postgraduate student from 2008 to 2010 . He is currently a Ph.D. candidate at Nanyang Technological University (NTU), Singapore. His current research interests include all electric ships, power electronics

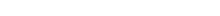

